\title{
The Model of Distributor Chain Financing Based on Buy Back Guarantee Contract
}

\author{
Jian-xin Chen ${ }^{1,2}$ and Jia-yin Chen $^{2}$ \\ ${ }^{1}$ Faculty of Applied Mathematics, Guangdong University of Technology, Guangzhou 510520, China \\ ${ }^{2}$ School of Business Administration, South China University of Technology, Guangzhou 510641, China \\ Correspondence should be addressed to Jian-xin Chen; chenjianxin403@163.com
}

Received 13 December 2013; Accepted 11 August 2014; Published 20 August 2014

Academic Editor: X. Zhang

Copyright (C) 2014 J.-x. Chen and J.-y. Chen. This is an open access article distributed under the Creative Commons Attribution License, which permits unrestricted use, distribution, and reproduction in any medium, provided the original work is properly cited.

\begin{abstract}
This paper considers the strategy employed by a buy back guarantee contract with a capital-constrained distributor and a core enterprise. The distributor faces a nonnegative random demand, and the core enterprise applies buy back guarantee contract in order to interact with the capital-constrained distributor. Mathematical model is built to get the optimal ordering quantity of the distributor and the optimal wholesale price of the core enterprise. Then sensitivity analysis of optimal ordering quantity is obtained about the wholesale price, the initial funds, and the salvage of the product. On that basis, the comparison is made between two financing modes - trade credit contract and buy back guarantee contract. In the end, a numerical analysis is illustrated. The results show that the different financing modes bring the different expected profits to supply chain system with the different initial funds, finding that the financing modes, buy back guarantee contract discussed in the paper, can create more value for supply chain system than trade credit contract.
\end{abstract}

\section{Introduction}

With the rapid development of science and technology and the coming of the information age, the relation between supply chain enterprises is unavoidable more and more close in three aspects of information flow, cash flow, and logistics. Recently supply chain management has been more and more perfect in the information flow and logistics. However, the equally important cash flow has not been synchronized with development and the related academic research is also relatively scarce. Capital constraints are a real problem that small and medium-sized enterprises (SMEs) can face when they enter the production and sales chain. Obtaining sufficient capital to finance these elements of their operations is a challenge for SMEs worldwide. Capital constraints are one of the factors that must be considered in the production operations and inventory decisions. Due to the lag of the cash flow management research, it is difficult to synchronize the logistics and information flow. In traditional supply chain research they often supposed the capital of SMEs was sufficient. Caldentey and Haugh pointed out that capital constraints were the common problem in supply chain management practice. Buzacott and Zhang [1] researched the strategy of the enterprise under capital constraints and their results were published in Management Science in 2004. This shows that the research fields were beginning to receive attention. Then $\mathrm{Xu}$ and Birge [2] assumed that the demand was uncertain and the market was not perfect; the joint decision problem between enterprise financing and production was discussed. They also discussed the mutual influence of the enterprise's productivity and long-term capital structure. Applying principal agent theory and the newsvendor model, Xu and Brige [3] established the model of enterprise capital structure, management incentives, and production decision. Swinney et al. [4] studied the influence of enterprise bankruptcy risk to the newly established enterprise investment decision. They chose the survival probability as the objective decision for newly established enterprise and made the comparison with the mature enterprise whose decision was the profit maximization. Li et al. [5] studied a dynamic model of coordination in an equity financed firm in which inventory and financial decisions interact in the 
presence of demand uncertainty, capital constraints, and a risk of default. Babich et al. [6] identified several economic and business factors that might affect the number of suppliers: supply risk, fixed costs of working with suppliers, and access to financing. Xu and Zhang [7] allowed a manufacture to offer loans and provide goods to its capital-constrained retailers in a monopoly setting. They examined whether the typical supply chain contract could achieve channel coordination. Dada and $\mathrm{Hu}$ [8] pointed out that when cost of borrowing was not too high, the capital-constrained newsvendor borrowed funds to procure an amount that was less than would be ideal. The lender charged an interest rate that decreased in the newsvendor's equity and they derived a nonlinear loan schedule that coordinates the channel. Gupta [9] chose the discount rate of the retailer advance payment as the sole decision variables of the supplier under the assumption of unchanged wholesale price. Lai et al. [10] examined the impact of capital constraints and investigated the supply chain efficiency under each mode. Based on a Stackelberg game with the supplier being the leader, they showed that without financial constraint the supplier always preferred the consignment mode, taking full inventory risk. They also showed that, with capital constraints, the combination mode was the most efficient mode even if the retailer earned zero internal capital. Kouvelis and Zhao [11] considered a supply chain with a retailer and a supplier: a newsvendor-like retailer had a single opportunity to order products from a supplier to satisfy future uncertain demand. Both the retailer and supplier were capital constraints and in need of short-term financing. They used the supplier early payment discount scheme as a decision framework to analyze all decisions involved in optimally structuring the trade credit contract from the supplier's perspective. Kouvelis and Zhao [12] studied a supply chain of a supplier selling via a wholesale price contract to a capital-constrained retailer who faced stochastic demand. They identified the retailer's optimal order quantity as a function of the wholesale price and his total wealth. The analysis of the supplier's optimal wholesale price problem as a Stackelberg game, with the supplier the leader and the retailer the follower, led to unique equilibrium solution in wholesale price and ordering quantity, with the equilibrium ordering quantity smaller than the traditional newsvendor one. Chen and Wan [13] examined the impact of financing on the performance of a two-level supply chain consisting of a supplier and a capital-constrained retailer. They set up a three-stage Stackelberg game under a wholesale price contract with a financial market and demonstrated that, in a competitive financial market with symmetric information on the retailer's initial budget, the retailer's operational and financial decisions could be decoupled. Chen and Wang [14] investigated the impacts of trade credit and limited liability on the performance of a two-level supply chain with capital constraints. They found that trade credit contract could create value in a supply chain with capital constraints and partly coordinate the supply chain.

The motivation of the paper comes from the operations practice of Hengda Steel in China, a famous company that affords the goods buy back contract for the capitalconstrained distributor. Buy back guarantee contract is a kind of financing service provided by core enterprise through buy back guarantee of the real goods to facilitate downstream distributor's purchasing, in which core enterprise is the subject of risk control and the basis is the advance payment generated after downstream distributor and core enterprise signing a real business contract.

Our model differs from the previous work in the following aspects. First, we assume that the retailer is capital constraints. Capital flow is an important factor in supply chain, although the extant literatures typically assume that the retailers or distributors are deep pocket. Second, there is no model to discuss the strategy of the distributor and the core enterprise under the buy back guarantee contract (buy back guarantee contract will be discussed in detail in Section 2). In this paper, with the buy back guarantee contract we model the expected profits of the distributor and the core enterprise. Furthermore, we discuss the optimal ordering quantity of the distributor and the optimal wholesale price of the core enterprise, finding that the buy back guarantee contract could create value for the supply chain with capital constraints.

The remainder of the paper is organized as follows. Section 2 gives themodel description and assumptions. Section 3 discusses the expected profit models of distributor and the core enterprise, obtaining the optimal strategy of supply chain. Section 4 illustrates a numerical example.

\section{Model Description and Assumptions}

Buy back guarantee contract is a kind of financing service provided by core enterprise through buy back guarantee of the real goods to facilitate downstream distributor's purchasing. Core enterprise is the subject of risk control and the basis is the advance payment generated after downstream distributor and core enterprise signing a real business contract.

Hengda Steel, for example, is a core steel enterprise. If there is a steel distributor with 3 million self-funds wanting to purchase a batch of steel worth 10 million from the core steel enterprise, then it has to apply for fund by chain financing of buy back guarantee with the assistance of core steel enterprise, Hengda Steel Company. The following are the details.

(1) The bank, core enterprise, and distributor sign the contract, and the core enterprise promises to buy back the unsold steel when the bank's acceptance bill (BA) has reached the appointed date. The distributor should remit money into its appointed account in bank and authorize the bank to deduct the sales for financing.

(2) The distributor pays no less than $30 \%$ of the payment to core enterprise.

(3) The bank checks the core enterprise's line of credit and ratifies $\mathrm{BA}$ to the distributor.

(4) Core enterprise pays the guarantee money of the BA to the bank (generally $30 \%$ of the face value) and the core supplier gives it to core enterprise directly.

(5) Core supplier delivers to the distributor after receiving $\mathrm{BA}$ and sends the certificate of the steel to the bank. 


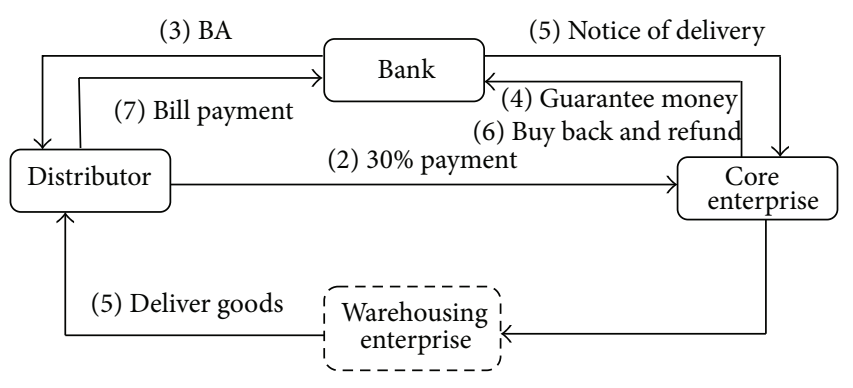

FIGURE 1: The process of buy back guarantee contract.

(6) Distributor remits the sales to the appointed account in bank after selling steel to redeem certificates to fulfill selling.

(7) If the distributor sells all steel when the BA is due, the bank withdraws the capital and releases the BA. If the distributor fails to sell all steel at the end of the selling period, the bank releases the BA after core enterprise buys back the unsold steel.

The implemented process is shown in Figure 1. The dashed box shows that warehousing enterprise is not required.

We consider a simple supply chain with a core enterprise and a capital-constrained distributor. The core enterprise produces a single product and the distributor faces a nonnegative random demand $\xi$ with a distribution function (similar to the model discussed in Cachon (2003) and Lariviere and Porteus (2001)). We formulate the interaction between the distributor and the core enterprise in the framework of a Stackelberg game. at the beginning of the selling period, the core enterprise as the Stacklberg leader and the distributor as the follower sign buy back guarantee contract. After the end of the selling period the enterprise buys back the left goods according to the exposure between bank acceptance and the cash deposit. Let us assume denotations as follows.

$\xi:$ market demand is a nonnegative random variable with probability density function $f(x)$ and the cumulative distribution function $F(x)$, respectively. Suppose the hazard function $h(x)=f(x) / \bar{F}(x)$ (IFR) and the generalized failure rate (GFR) $H(x)=$ $x f(x) / \bar{F}(x)$, where $\bar{F}(x)=1-F(x)$ is the tail distribution of $F(x)$.

$Q$ is the ordering quantity of the retailer.

$p$ is the unit retail price (suppose $p=1$ ).

$w$ is the wholesale price (the unit ordering cost).

$B$ is the initial capital of distributor.

$c$ is the unit production cost.

$s$ is the salvage of the product. Without loss of generality assume $p=1 \geq w>c>s$.

\section{Result Concerned with the Paper}

When the retailer has no capital constraints the profit of the retailer can be written as follows: $\min \{x, Q\}-w Q+s(Q-x)^{+}$. The profit of the supplier can be written as follows: $(w-c) Q$.

The optimal decentralized ordering quantity $Q_{0}$ is

$$
(1-s) \bar{F}\left(Q_{0}\right)=(w-s) .
$$

The optimal centralized ordering quantity $Q^{C}$ is

$$
(1-s) \bar{F}\left(Q^{C}\right)=(c-s) .
$$

We have $Q_{0}<Q^{C}$.

When the capital-constrained retailer (distributor) has no access to the financial market, its optimal ordering quantity is

$$
Q_{\mathrm{NF}}=\min \left\{\frac{B}{w}, Q_{0}\right\}
$$

(see [13]).

Under the trade credit contract the optimal inventory level of the retailer $Q^{T}$ is [14]

$$
(1-s) \bar{F}\left(Q^{T}\right)=(w-s) \bar{F}\left[\frac{(w-s)}{(1-s)} Q^{T}-\frac{B}{(1-s)}\right] .
$$

\section{Model Calculations}

4.1. The Distributor. The expected profit of the capitalconstrained distributor can be written as follows:

$$
\begin{aligned}
E \Pi^{R}= & \int_{0}^{w \mathrm{Q}-B}\left[s\left\{(Q-x)-\frac{1}{w}[(w Q-B)-x]\right\}-B\right] \\
& \times f(x) d x \\
& +\int_{w Q-B}^{Q}[x-(w Q-B)+s(Q-x)-B] f(x) d x \\
& +\int_{Q}^{+\infty}[Q-(w Q-B)-B] f(x) d x .
\end{aligned}
$$

Theorem 1. (i) Under buy back guarantee contract the optimal ordering quantity of the distributor is

$$
(1-s) \bar{F}\left(Q^{*}\right)-(w-s) \bar{F}\left(w Q^{*}-B\right)=0 .
$$

(ii) Under buy back guarantee contract the optimal ordering quantity of the distributor $Q^{*}$ decreases in $w$ and $B$.

Proof. (i) It is easy to get $\partial E \Pi^{R} / \partial Q=(1-w) \int_{Q}^{+\infty} f(x) d x-$ $(w-s) \int_{w \mathrm{Q}-B}^{\mathrm{Q}} f(x) d x$. If $\widehat{Q}$ satisfies $\partial E \Pi^{R} / \partial Q=0$, then $\partial^{2} E \Pi^{R} / \partial Q^{2}=-(1-s) \bar{F}(Q)\{h(Q)-w h(w Q-B)\}<0$. So the optimal ordering quantity is $(1-s) \bar{F}(Q)-(w-s) \bar{F}(w Q-B)=0$.

(ii) Let $G(Q, w)=(1-s) \bar{F}(Q)-(w-s) \bar{F}(w Q-B)$; then $\partial Q / \partial w=-\{1-(w-s) Q h(w Q-B)\} /(w-s)\{h(Q)-w h(w Q-$ $B)\}$. 
According to the assumption we have $w \in[s, 1]$. Suppose $M_{2}(w)=(w-s) \bar{F}(w Q-B)$; then $M_{2}^{\prime}(w)=\bar{F}(w Q-B)[1-$ $(w-s) Q h(w Q-B)]$.

$\bar{F}(w Q-B)$ and $[1-(w-s) Q h(w Q-B)]$ both decrease in $w$ as the IFR property of random demand $\xi$. Then $M_{2}(w)$ is unimodal in $w$ and achieves the maximum at $1=(w-$ $s) Q h(w Q-B)$. We have $M_{2}(s)=0$ and $M_{2}(1)=(1-s) \bar{F}(Q-$ $B)>(1-s) \bar{F}(Q)$.

We conclude that, for $w \in[s, 1],(1-s) \bar{F}(Q)=(w-$ s) $\bar{F}(w Q-B)$ can only be satisfied on the positive slope of $M_{2}(w)$, so $M_{2}^{\prime}(w)>0$, $[1-(w-s) Q h(w Q-B)]>0$, and $\partial Q / \partial w<0$. It is easy to get $\partial Q / \partial B=-h(w Q-B) /(h(Q)-$ $w h(w Q-B))<0$. This, then, indicates that Theorem 1 is correct.

Recall that, in the traditional newsvendor model (Hadley and Whitin 1963) with no capital constraints, the optimal ordering quantity of the retailer is (1). That is a first-order optimality condition that requires the marginal revenue of an extra unit, $(1-s) \bar{F}\left(Q_{0}\right)$, to be equal to the cost of this extra unit $(w-s)$.

Under buy back guarantee contract, the first-order optimality condition satisfies (6). Since $(w-s) \geq(w-s) \bar{F}\left(w Q^{*}-\right.$ $B)$, it follows that a distributor (retailer) has a lower marginal cost in this case and $Q^{*} \geq Q_{0}$. It is because that the low demand reduces the distributor's downside risk. Under the trade credit contract the distributor's (retailer's) optimal ordering quantity satisfies $(4)$; since $(w-s) \bar{F}[((w-s) /(1-$ s) $\left.) Q^{T}-B /(1-s)\right] \geq(w-s) \bar{F}\left(w Q^{*}-B\right)$, it follows that $Q^{*} \geq$ $Q^{T} \geq Q_{0} \geq Q_{\mathrm{NF}}$. In particular, $s=0$; the optimal ordering quantity of distributor (retailer) satisfies $\bar{F}(Q)-w \bar{F}(w Q-B)=$ 0 . It is equal to the optimal ordering quantity under trade credit contract [14]. At this time, the incentive effect of buy back guarantee contract and the trade credit contract is the same. Furthermore, Theorem 1 also shows that the optimal ordering quantity decreases in $B$; the reason why $\partial Q / \partial B<0$ is that the distributor with a low budget has little stake at risk when choosing its ordering quantity in the sense that its potential losses are bounded by $B$; on the other hand the reason is the incentive effect of the buy back guarantee contract.

Theorem 2. Under buy back guarantee contract the optimal order quantity of distributor $Q^{*}$ increases in $s$.

Proof. Let $G(Q, w)=(1-s) \bar{F}(Q)-(w-s) \bar{F}(w Q-B)$.

Then

$$
\frac{\partial Q}{\partial s}=-\frac{[\bar{F}(Q)-\bar{F}(w Q-B)]}{(w-s) \bar{F}(w Q-B)[h(Q)-w h(w Q-B)]}>0 .
$$

The increase of $s$ reduces the random market risk of distributor faces and increases the expected profit of distributor, so the distributor will increase the optimal ordering quantity to raise profit.
4.2. The Core Enterprise. The expected profit of the core enterprise can be written as follows:

$$
\begin{aligned}
E \Pi_{M}= & \int_{0}^{w Q-B}\left\{Q-\frac{[(w Q-B)-x]}{w}\right\}(w-c) f(x) d x \\
& +\int_{w Q-B}^{+\infty}(w-c) Q f(x) d x .
\end{aligned}
$$

Lemma 3. The optimal ordering quantity of distributor $Q$ satisfies $\partial^{2} Q / \partial w^{2}<0$.

Proof. Let

$$
\frac{\partial Q}{\partial w}=-\frac{\{1-(w-s) Q h(w Q-B)\}}{(w-s)\{h(Q)-w h(w Q-B)\}} .
$$

Then

$$
\begin{gathered}
\frac{d E \Pi_{M}}{d w}=\frac{\partial E \Pi_{M}}{\partial Q} \frac{\partial Q}{\partial w}+\frac{\partial E \Pi_{M}}{\partial w} \\
=(w-c) \bar{F}(w Q-B) \frac{\partial Q}{\partial w} \\
+\left[Q \bar{F}(w Q-B)+\frac{B c}{w^{2}} F(w Q-B)\right. \\
\left.\quad+\frac{c}{w^{2}} \int_{0}^{w Q-B} x d F(x)\right], \\
\frac{\partial^{2} Q}{\partial w^{2}}=-\left(\frac{\bar{F}(w Q-B)[1-(w-s) Q h(w Q-B)]}{(1-s) f(Q)-(w-s) w f(w Q-B)}\right)_{w}^{\prime} ;
\end{gathered}
$$

then

$$
\begin{aligned}
\left(\frac{\bar{F}(w Q-B)[1-(w-s) Q h(w Q-B)]}{(1-s) f(Q)-(w-s) w f(w Q-B)}\right)_{w}^{\prime} \\
=\frac{\{\bar{F}(w Q-B)[1-(w-s) Q h(w Q-B)]\}_{w}^{\prime}}{[(1-s) f(Q)-(w-s) w f(w Q-B)]^{2}} \\
\quad \times[(1-s) f(Q)-(w-s) w f(w Q-B)] \\
-\frac{[(1-s) f(Q)-(w-s) w f(w Q-B)]_{w}^{\prime}}{[(1-s) f(Q)-(w-s) w f(w Q-B)]^{2}} \\
\quad \times\{\bar{F}(w Q-B)[1-(w-s) Q h(w Q-B)]\} \\
=\frac{\left\{-2 Q f(w Q-B)-(w-s) Q^{2} f^{\prime}(w Q-B)\right\}}{[(1-s) f(Q)-(w-s) w f(w Q-B)]^{2}} \\
\quad \times[(1-s) f(Q)-(w-s) w f(w Q-B)]
\end{aligned}
$$




$$
\begin{aligned}
& -\frac{\left[-(2 w-s) f(w Q-B)-(w-s) w Q f^{\prime}(w Q-B)\right]}{[(1-s) f(Q)-(w-s) w f(w Q-B)]^{2}} \\
& \times\{\bar{F}(w Q-B)[1-(w-s) Q h(w Q-B)]\} \\
= & \frac{1}{w Q} \frac{\left\{-2 w Q f(w Q-B)-(w-s) w Q^{2} f^{\prime}(w Q-B)\right\}}{[(1-s) f(Q)-(w-s) w f(w Q-B)]^{2}} \\
& \times[(1-s) Q f(Q)-(w-s) w Q f(w Q-B)] \\
& +\frac{1}{w Q}[(2 w-s) Q f(w Q-B) \\
& \times\left([(1-s) f(Q)-(w-s) w f(w Q-B)]^{2}\right)^{-1} \\
& \times[w \bar{F}(w Q-B)-(w-s) w Q f(w Q-B)] \\
= & \frac{1}{w Q} \frac{-\left\{2 w Q f(w Q-B)+(w-s) w Q^{2} f^{\prime}(w Q-B)\right\}}{[(1-s) f(Q)-(w-s) w f(w Q-B)]^{2}} \\
& \times[(1-s) Q f(Q)-(w-s) w Q f(w Q-B)] \\
& +\frac{1}{w Q}\left[2 w Q f(w Q-B)+(w-s) w Q^{2} f^{\prime}(w Q-B)\right. \\
& \times[(w Q[(w-s) \bar{F}(w Q-B)-(w-s) w Q f(w Q-B) \\
& +s \bar{F}(w Q-B)] \\
& \quad-s Q f(w Q-B)] \\
& \left.+(1-s) f(Q)-(w-s) w f(w Q-B)]^{2}\right)^{-1}
\end{aligned}
$$

where

$$
\begin{aligned}
\Delta_{1}=\{ & -\left[2 w Q f(w Q-B)+(w-s) w Q^{2} f^{\prime}(w Q-B)\right] \\
& \times[(1-s) Q f(Q)-(w-s) w Q f(w Q-B)] \\
& +\left[2 w Q f(w Q-B)+(w-s) w Q^{2} f^{\prime}(w Q-B)\right] \\
& \times[(w-s) \bar{F}(w Q-B)-(w-s) w Q f(w Q-B)]\} \\
= & {\left[2 w Q f(w Q-B)+(w-s) w Q^{2} f^{\prime}(w Q-B)\right] } \\
& \times(1-s) \bar{F}(w Q-B)\{1-Q h(Q)\} .
\end{aligned}
$$

Since the demand distribution has the property of IFR, $\Delta_{1}>$ 0 :

$$
\begin{aligned}
\Delta_{2}= & -s Q f(w Q-B) \\
& \times[w \bar{F}(w Q-B)-(w-s) w Q f(w Q-B)] \\
& +s \bar{F}(w Q-B) \\
& \times\left[(2 w-s) Q f(w Q-B)+(w-s) w Q^{2} f^{\prime}(w Q-B)\right] \\
= & (w-s) w s f^{2}(w Q-B)+(w-s) s Q f(w Q-B) \\
& \times \bar{F}(w Q-B)[1-w Q h(w Q-B)]>0 .
\end{aligned}
$$

So $\partial^{2} Q / \partial w^{2}<0$.

Theorem 4. Under buy back guarantee contract the optimal wholesale price of the core enterprise $w^{*}$ can be expressed as follows:

$$
\begin{aligned}
& (w-c) \bar{F}(w Q-B) \frac{\partial Q}{\partial w} \\
& \quad+\left[Q \bar{F}(w Q-B)+\frac{B c}{w^{2}} F(w Q-B)+\frac{c}{w^{2}} \int_{0}^{w Q-B} x d F(x)\right] \\
& =0 .
\end{aligned}
$$

Proof. Consider

$$
\begin{aligned}
\frac{d^{2} E \Pi_{M}}{d w^{2}}= & 2 \bar{F}(w Q-B) \frac{\partial Q}{\partial w}[1-(w-c) Q h(w Q-B)] \\
& -(w-c) w f(w Q-B)\left(\frac{\partial Q}{\partial w}\right)^{2} \\
& +(w-c) \bar{F}(w Q-B) \frac{\partial^{2} Q}{\partial w^{2}} \\
& -\left(1-\frac{c}{w}\right) Q^{2} f(w Q-B)-2 \frac{B c}{w^{3}} F(w Q-B) \\
& -2 \frac{c}{w^{3}} \int_{0}^{w Q-B} x f(x) d x<0 .
\end{aligned}
$$

From Lemma 3, the optimal wholesale price of the core enterprise can be expressed as follows:

$$
\begin{aligned}
& (w-c) \bar{F}(w Q-B) \frac{\partial Q}{\partial w}+Q \bar{F}(w Q-B)+\frac{B c}{w^{2}} F(w Q-B) \\
& +\frac{c}{w^{2}} \int_{0}^{w Q-B} x d F(x)=0 .
\end{aligned}
$$

\section{Numerical Example}

Figure 2 gives the relation between the distributor's initial capital and the optimal ordering quantity. We assume that 


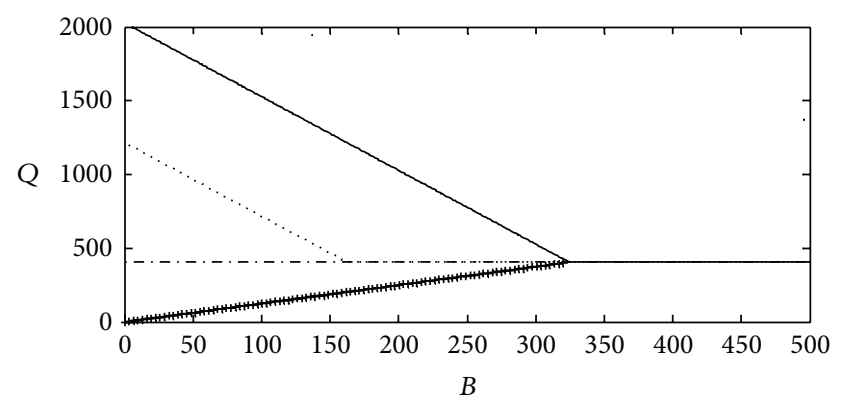

__ Retailer's optimal ordering level under buy back guarantee contract

..... Retailer's optimal ordering level under trade credit contract

- . - The optimal ordering level in traditional newsvendor model

$\rightarrow$ Retailer's optimal ordering level without financing

FIGURE 2: Relation between the optimal ordering quantities with different financial modes.

TABLE 1: Optimal ordering quantity of the distributor and the total profit of supply chain system.

\begin{tabular}{|c|c|c|c|c|c|}
\hline \multirow{4}{*}{$B$} & \multicolumn{5}{|c|}{$Q$} \\
\hline & $Q_{\mathrm{NF}}$ & $Q_{0}$ & $Q^{T}$ & $Q^{*}$ & $Q^{C}$ \\
\hline & & & $\Pi$ & & \\
\hline & $\Pi_{\mathrm{NF}}$ & $\Pi_{0}$ & $\Pi^{T}$ & $\Pi^{*}$ & $\Pi^{C}$ \\
\hline \multirow{2}{*}{$B=50$} & 63 & 405 & 935 & 1406 & 1766 \\
\hline & 30 & 159 & 243 & 404 & 321 \\
\hline \multirow{2}{*}{$B=100$} & 125 & 405 & 709 & 1237 & 1766 \\
\hline & 58 & 159 & 236 & 374 & 321 \\
\hline \multirow{2}{*}{$B=200$} & 250 & 405 & 405 & 866 & 1766 \\
\hline & 89 & 159 & 192 & 294 & 321 \\
\hline \multirow{2}{*}{$B=400$} & 405 & 405 & 405 & 405 & 1766 \\
\hline & 158 & 160 & 192 & 159 & 321 \\
\hline
\end{tabular}

$p=1, w=0.8$, and $s=0.4$ and $\xi \sim$ exponential (1/1000). From Figure 2 we know that the optimal ordering quantity $Q^{*}$ is bigger than $Q^{T}$, the optimal ordering quantity of the trade credit contract. The optimal ordering quantities $Q^{*}$ and $Q^{T}$ are both bigger than $Q_{\mathrm{NF}}$, the optimal ordering quantity of the retailer without financing service. It also indicates that the $Q^{*}$ decreases in the initial budget $B$ of the retailer. These conclusions are all consistent with Theorem 1 .

Let $\Pi_{\mathrm{NF}}, \Pi_{0}, \Pi^{T}, \Pi^{*}$, and $\Pi^{\mathrm{C}}$ be the total expected profits of supply chain without system finance, the traditional newsvendor model, traded credit financing, buy back guarantee financing, and the centralized decision without finance. With the change of the initial capital, let $B=50,100,200$, and 400 ; Table 1 gives the optimal ordering quantity of the retailer and the total profit of supply chain system.

\section{Conclusions}

Working under the assumption of stochastic market demand and a distributor, that is, capital constraints, this paper has considered the optimal ordering quantity of the distributor and the wholesale price of the core enterprise with buy back guarantee contract in a single stage supply chain system. We compare the optimal ordering quantities of the different financing modes: trade credit contract, the traditional newsvendor model and buy back guarantee contract. The study has highlighted how the capital-constrained distributor could be financed well facing different financing modes and the research results show that the different financing modes bring different expected profits for supply chain system with the capital-constrained distributor. The results could be applied for the distributor and the core enterprise when they make decisions in reality. The paper has also raised the potential for further research into finance contact of supply chain, where more than one distributor and core enterprise can also be considered.

\section{Conflict of Interests}

The authors declare that there is no conflict of interests regarding the publication of this paper.

\section{Acknowledgments}

This work was financially supported by the Key Project of the National Natural Science Foundation of China (71131003), Project of the National Natural Science Foundation of China (71371075), China Postdoctoral Science Foundation funded Project (2013M542183), Guangdong Province Natural Science Fund (S2013040014920) of China, and Research Fund for the Doctoral Program of Guangdong University of Technology of China (13ZK0155).

\section{References}

[1] J. A. Buzacott and R. Q. Zhang, "Inventory management with asset-based financing," Management Science, vol. 50, no. 9, pp. 1274-1292, 2004.

[2] X. D. Xu and J. R. Birge, "Joint production and financing decisions: modeling and analysis," Working Paper, The University of Chicago Graduate School of Business, 2004.

[3] X. D. Xu and J. R. Birge, "Operational decisions, capital structure, and managerial compensation: a news vendor perspective," Working Paper, The University of Chicago Graduate School of Business, 2005.

[4] R. Swinney, G. Cachon, and S. Netessine, "Capacity investment by competitive startups," Working Paper, The Wharton School, University of Pennsylvania, 2005.

[5] L. Li, M. Shubik, and M. Sobel, "Control of dividends, capital subscriptions, and physical inventories," Working Paper, Yale School of Management, 2005.

[6] V. Babich, G. Aydin, P. Brunet, J. Keppo, and R. Saigal, "Risk, financing and optimal number of suppliers," Working Paper, IOE, University of Michigan, Ann Arbor, Mich, USA, 2005.

[7] Y. Xu and J. Zhang, "On the selection of supply chain coordinating contracts: the role of capital constraint," Working Paper, University of Miami, 2007.

[8] M. Dada and Q. Hu, "Financing newsvendor inventory," Operations Research Letters, vol. 36, no. 5, pp. 569-573, 2008. 
[9] D. Gupta, “Technical note: financing the newsvendor," Working Paper, Industrial and Systems Engineering, University of Minnesota, 2008.

[10] G. Lai, L. G. Debo, and K. Sycara, "Sharing inventory risk in supply chain: the implication of financial constraint," Omega, vol. 37, no. 4, pp. 811-825, 2009.

[11] P. Kouvelis and H. W. Zhao, "Financing the Newsvendor: Supplier vs. Bank, and the Structure of Optimal Trade Credit Contracts," Working paper, Olin Business School, Washington University, September 2009.

[12] P. Kouvelis and W. H. Zhao, "The newsvendor problem and price-only contract when bankruptcy costs exist," Working Paper, Olin Business School, Washington University, 2010.

[13] X. F. Chen and G. Wan, "The effect of financing on a budgetconstrained supply chain under wholesale price contract," AsiaPacific Journal of Operational Research, vol. 28, no. 4, pp. 457485, 2011.

[14] X. F. Chen and A. Wang, "Trade credit contract with limited liability in the supply chain with budget constraints," Annals of Operations Research, vol. 196, pp. 153-165, 2012. 


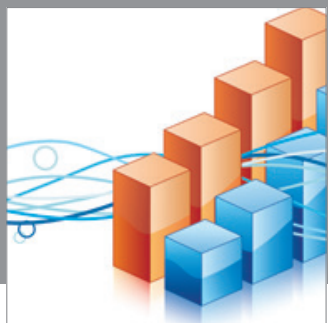

Advances in

Operations Research

mansans

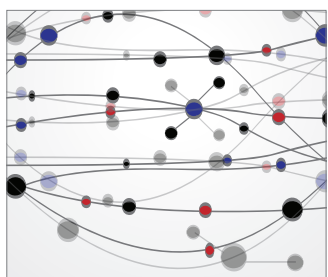

The Scientific World Journal
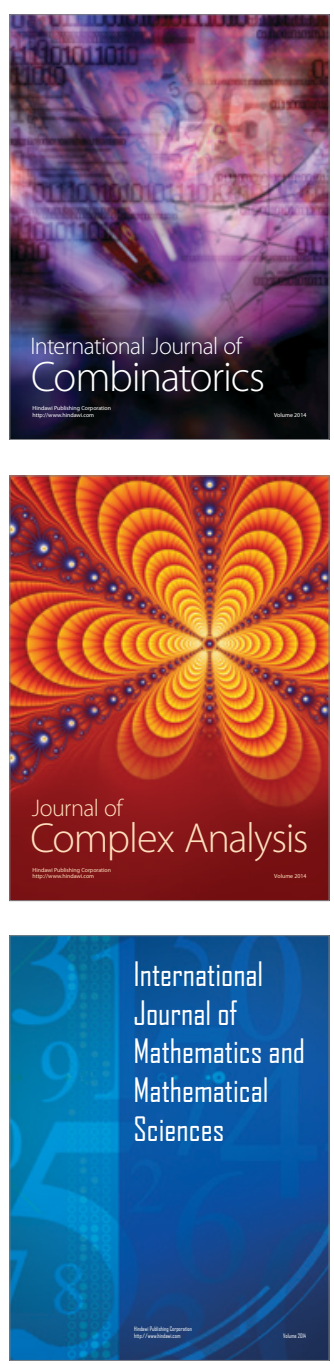
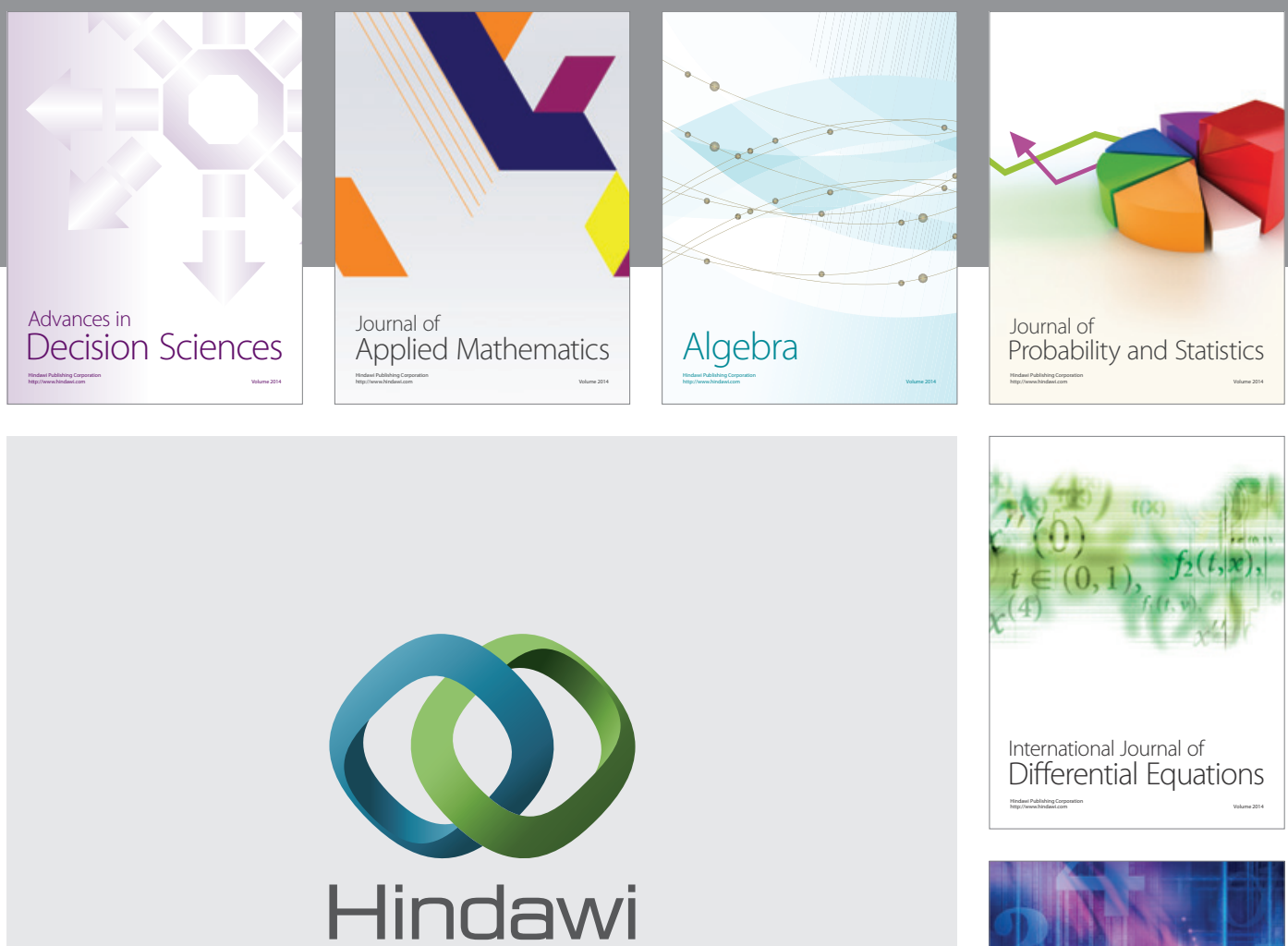

Submit your manuscripts at http://www.hindawi.com
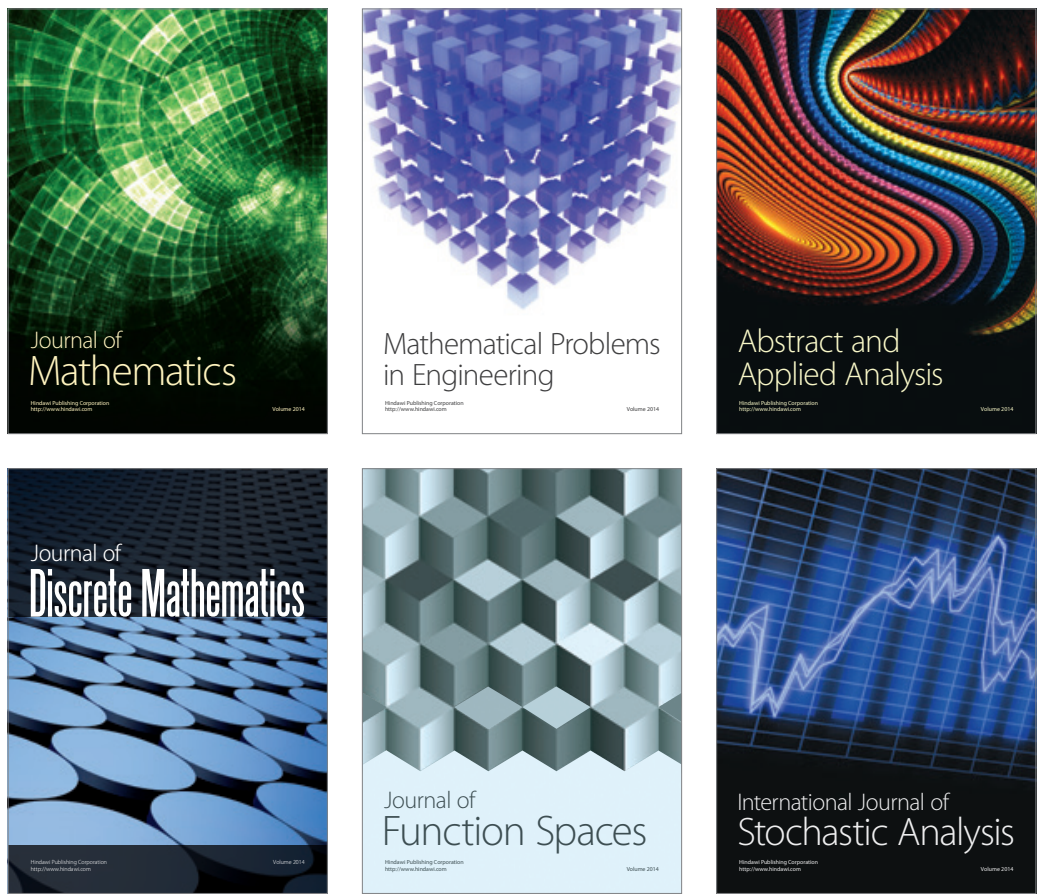

Journal of

Function Spaces

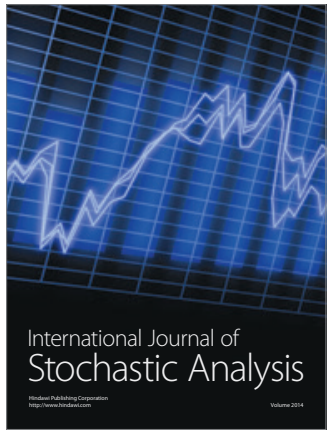

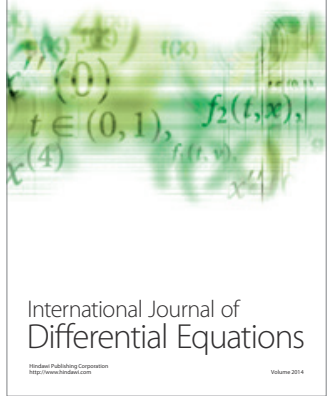
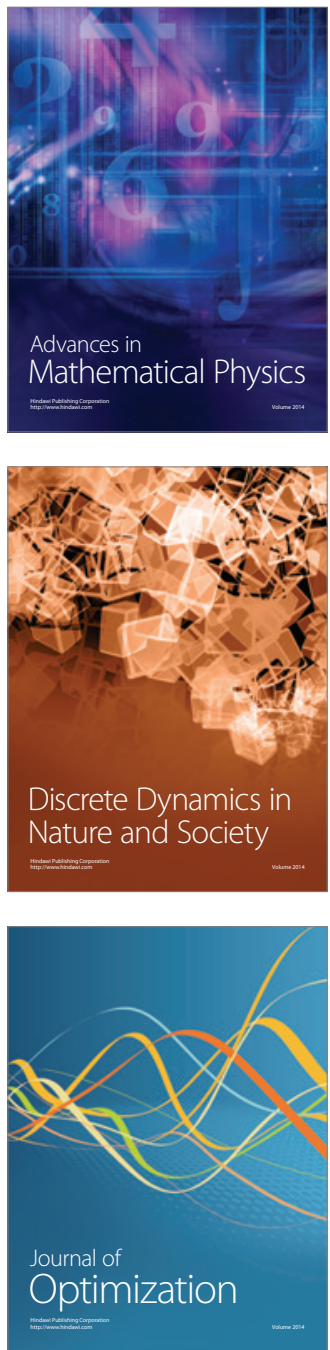